\title{
Tingkat Kepuasan Mahasiswa Terhadap Pelayanan Akademik Pada Program Diploma Pelayaran Universitas Hang Tuah Surabaya
}

\author{
Faulina Khusniawati ${ }^{(1)}$, Maxima Ari Saktiono ${ }^{(2)}$ \\ Universitas Hang Tuah Surabaya \\ Jl. Arief Rachman Hakim No. 150 Telp. (031) 5945864 Surabaya 60111 \\ e-mail: faulina.khusniawati@hangtuah.ac.id dan maxima.ari@hangtuah.ac.id
}

\begin{abstract}
ABSTRAK
Variabel dalam penelitian ini ada satu yaitu kepuasan mahasiswa terhadap pelayanan akademik. Populasi dalam penelitian ini adalah mahasiswa aktif di Fakultas Program Diploma Pelayaran Surabaya yang berjumlah 100 orang. Instrumen yang digunakan dalam penelitian ini adalah kuesioner untuk mendapatkan skor kepuasan mahasiswa terhadap pelayanan akademik. Teknik analisis data yang digunakan yaitu teknik analisis deskriptif kuantitatif untuk menjawab rumusan masalah. Melalui metode dan analisis data tersebut menunjukkan bahwa tingkat kepuasan mahasiswa terhadap pelayanan akademik pada Fakultas Program Diploma Pelayaran Surabaya adalah mahasiswa yang berada dalam kategori tinggi adalah 20 orang dengan persentasi $20 \%$, dan yang berada dalam kategori sedang adalah 72 orang dengan persentasi $72 \%$, sedangkan dengan kategori rendah adalah 8 orang dengan persentase $8 \%$. Dengan demikian tingkat kepuasan mahasiswa terhadap pelayanan akademik pada Fakultas Program Diploma Pelayaran Surabaya berada pada kategori sedang yaitu 72 mahasiswa dengan persentasi $72 \%$.
\end{abstract}

Kata kunci : Tingkat Kepuasan, Analisis Deskriptif

\begin{abstract}
There is one variable in this study, namely student satisfaction with academic services. The population in this study were 100 active students in the Faculty of Shipping Diploma Program in Surabaya. The instrument used in this study was a questionnaire to obtain student satisfaction scores on academic services. The data analysis technique used is descriptive quantitative analysis technique to answer the problem formulation. Through these methods and data analysis, it shows that the level of student satisfaction with academic services at the Surabaya Shipping Diploma Program is 20 students with a percentage of 20\%, and 72 people in the medium category with a percentage of $72 \%$, while with the low category is 8 people with a percentage of $8 \%$. Thus the level of student satisfaction with academic services at the Faculty of Shipping Diploma Program in Surabaya is in the medium category, namely 72 students with a percentage of $72 \%$.

Keywords : Satisfaction Level, Descriptive Analysis
\end{abstract}

\section{PENDAhuluan}

Perguruan tinggi yang berkualitas merupakan idaman bagi para calon mahasiswa yang ingin melanjutkan studinya ke jenjang yang lebih tinggi. Para calon mahasiswa dan mahasiswi merupakan pelanggan bagi perguruan tinggi. Mereka membutuhkan pelayanan dalam memenuhi harapannya, sehingga para pelanggan ini merupakan nilai utama dalam mengaktualisasikan lembaga pendidikan tersebut kepada masyarakat bahwasannya perguruan tinggi tersebut berkualitas. Meskipun pelayanan disebut sebagai sesuatu yang tidak nyata tidak seperti suatu barang yang dijual akan tetapi mahasiswa (konsumen) dapat menilai pelayanan layaknya suatu barang bermutu atau tidak bermutu. (Suhartini,2012)

Perguruan tinggi merupakan lembaga pendidikan yang bergerak di bidang jasa harus mampu memberikan pelayanan yang baik inilah yang akan menciptakan citra yang baik dan menciptakan kualitas mahasiswa sebagai pelanggan. Pelayanan perlu mendapatkan perhatian besar dari perguruan tinggi, sebab kualitas pelayanan yang rendah akan menempatkan pemahaman pada posisi yang kurang menguntungkan sehingga mahasiswa sebagai konsumen merasa kurang puas. Kepuasan kansumen merupakan evaluasi purna beli dimana alternatif yang dipilih sekurang-kurangnya sama 
atau melampui harapan pelanggan, sedangkan ketidakpuasan timbul apabila hasil (outcome) yang tidak memenuhi harapan (Tjiptono, 2010).

Tingkat kepuasan adalah perbedaan antara daya guna yang dirasakan dan harapan, terdapat bebrapa tingkat kepuasan, di antaranya adalah :

a. Tidak puas adalah kondisi dimana pelanggan (mahasiswa) merasakan daya guna suatu produk atau jasa berupa pelayanan lebih rendah dari harapan.

b. Puas adalah kondisi dimana pelanggan (mahasiswa) merasakan daya guna suatu produk atau jasa berupa pelayanan sesuai dengan harapan.

c. Sangat puas adalah kondisi dimana pelanggan (mahasiswa) merasakan daya guna suatu produk atau jasa berupa pelayanan dapat melebihi harapan pelanggan.

Adapun layanan yang diberikan oleh fakultas sebagai program yang harus diberikan sesuai dengan keinginan dan kebutuhan mahasiswa seperti : Pengajuan judul skripsi, pengesahan dan penetapan dosen pembimbing, cuti akademik, pembayaran SPP, ujian akhir semester, ujian tengah semester, pelaksanaan praktek / praktikum, pengurusan Ijazah, legalisasi ijazah, pengurusan $\mathrm{KRS}$, pengurusan transkrip nilai, bimbingan Akademik, perbaikan nilai, sidang tugas akhir, pelaksanaan wisuda

\section{METODE PENELITIAN \\ 2.1. Lokasi Penelitian}

Pada penelitian ini untuk memperoleh dan mengumpulkan data, peneliti melakukan penelitian pada Program Diploma Pelayaran Universitas hang Tuah Surabaya.

\subsection{Sumber Data}

Dalam penelitian ini, data yang digunakan adalah data primer yang merupakan data kuisioner mahasiswa aktif yang berjumlah 100 mahasiswa. Data primer adalah data yang diperoleh secara langsung dari responden dengan menggunakan kuesioner atau daftar pertanyaan yang telah disusun berdasarkan variabel-variabel yang diteliti. Data tersebut berupa jawaban dari responden.

Teknik pengumpulan data yang digunakan dalam penelitian ini adalah penyebaran kuesioner kepada responden dengan mengajukan pertanyaan yang telah disusun untuk membantu responden dalam memberikan jawaban. Pengukuran variabel dalam penelitian ini menggunakan skala likert 4 poin dimana masing-masing pertanyaan diberi skor 1 sampai dengan 4. Rentang skala dimulai 1 sampai
4, dimana angka 1 menunjukkan "sangat tidak setuju" (berarti pendapat responden sama sekali tidak sesuai dengan pernyataan dalam kuesioner) sampai dengan angka 4 yang berarti "sangat setuju" (berarti pendapat responden sangat sesuai dengan pernyataan dalam kuesioner). (Azwar, 2015)

\subsection{Langkah-langkah Penelitian}

Adapun langkah-langkah dalam menyusun tabel distribusi frekuensi adalah sebagai berikut:

1. Pertama-tama adalah menjumlahkan total nilai dari kuisioner masing-masing mahasiswa, kemudian mencari rentang (R) dengan menghitung selisih dari nilai tetinggi dan nilai terendah

$$
\begin{aligned}
& \mathrm{R}=\mathrm{NT}-\mathrm{NR} \\
& \mathrm{R}=(60-36) \\
& \mathrm{R}=24
\end{aligned}
$$

2) Menghitung banyaknya kelas interval

Banyaknya kelas interval disingkat dengan I dengan $\mathrm{n}$ merupakan jumlah sampel

$$
\begin{aligned}
& i=1+(3,33) \log n \\
& i=1+3,33 \times \log 100 \\
& i=1+3,3 \times 2=8
\end{aligned}
$$

3) Menghitung panjang interval

Panjang kelas interval yang disingkat dengan $\mathrm{P}$ dapat dihitung dengan cara :

$$
\begin{aligned}
& P=\frac{\text { Rentang }}{\text { Banyak Kelas }} \\
& P=\frac{24}{8}=3
\end{aligned}
$$

4) Membuat Tabel Distribusi Frekuensi Tingkat Kepuasan Mahasiswa Terhadap Pelayanan Akademik pada Fakultas Program Diploma Pelayaran Universitas Hang Tuah Surabaya

Tabel 4.2 Tabel Distribusi Frekuensi

\begin{tabular}{|l|l|}
\hline Intreval & $\mathrm{Fi}$ \\
\hline $36-38$ & 1 \\
\hline $39-41$ & 5 \\
\hline $42-44$ & 25 \\
\hline $45-47$ & 26 \\
\hline $48-50$ & 15 \\
\hline $51-53$ & 6 \\
\hline $54-56$ & 3 \\
\hline $57-59$ & 6 \\
\hline $60-62$ & 13 \\
\hline Total & 100 \\
\hline
\end{tabular}

5) Menghitung nilai rata-rata (mean) 
Tabel 4.3 Tabel Penolong Menghitung Nilai Mean

\begin{tabular}{|l|l|l|r|}
\hline Intreval & $\mathrm{Fi}$ & $\mathrm{Xi}$ & Fi.Xi \\
\hline $36-38$ & 1 & 37 & 37 \\
\hline $39-41$ & 5 & 40 & 200 \\
\hline $42-44$ & 25 & 43 & 1075 \\
\hline $45-47$ & 26 & 46 & 1196 \\
\hline $48-50$ & 15 & 49 & 735 \\
\hline $51-53$ & 6 & 52 & 312 \\
\hline $54-56$ & 3 & 55 & 165 \\
\hline $57-59$ & 6 & 58 & 348 \\
\hline $60-62$ & 13 & 61 & 793 \\
\hline Total & 100 & & 4861 \\
\hline
\end{tabular}

$\bar{x}=\frac{\sum f_{i} x_{i}}{\sum f_{i}}$

$\bar{x}=\frac{4861}{100}=48,61=49$

6) Menghitung nilai presentase

Tabel 4.4 Tabel Penolong Nilai Presentase

\begin{tabular}{|l|l|l|}
\hline Intreval & $\mathrm{Fi}$ & $\%$ \\
\hline $36-38$ & 1 & 1 \\
\hline $39-41$ & 5 & 5 \\
\hline $42-44$ & 25 & 25 \\
\hline $45-47$ & 26 & 26 \\
\hline $48-50$ & 15 & 15 \\
\hline $51-53$ & 6 & 6 \\
\hline $54-56$ & 3 & 3 \\
\hline $57-59$ & 6 & 6 \\
\hline $60-62$ & 13 & 13 \\
\hline Total & 100 & 100 \\
\hline
\end{tabular}

Penyajian data tersebut di atas yang merubah frekuensi menjadi persen (\%), dengan memperhatikan 100 mahasiswa sebagai sampel, $1 \%$ mahasiswa berada dalam interval (36-38), $5 \%$ mahasiswa berada dalam interval (39-41), $25 \%$ mahasiswa berada dalam interval (42-44), $26 \%$ mahasiswa berada dalam interval (45-47), $6 \%$ mahasiswa berada dalam interval (51-53), $3 \%$ mahasiswa berada dalam interval (54-56), $6 \%$ mahasiswa berada dalam interval (57-59), $13 \%$ mahasiswa berada dalam interval (60-62), dengan demikian dapat disimpulkan bahwa skor tingkat kepuasan mahasiswa terhadap pelayanan akademik yang diperoleh dari hasil angket, skor terendah 36 dan skor tertinggi 60 , dengan ratarata tingkat nilai persentase tingkat kepuasan mahasiswa terhadap pelayanan akademik pada Program Diploma Pelayaran (45-47) dengan nilai $26 \%$ yang diperoleh dari $26: 100 \times 100 \%$.

7) Menghitug nilai standar deviasi
Tabel 4.5 Tabel Penolong Standar Deviasi

\begin{tabular}{|c|c|c|c|c|c|c|}
\hline $\begin{array}{l}\text { Intrev } \\
\text { al }\end{array}$ & $\mathrm{Fi}$ & $\begin{array}{l}X \\
\text { i }\end{array}$ & $\begin{array}{l}\text { Fi. } \\
\mathrm{Xi}\end{array}$ & $\begin{array}{l}\mathrm{X} \\
\mathrm{i} \\
- \\
\bar{x}\end{array}$ & $\begin{array}{c}(\mathrm{Xi}- \\
\bar{x} \\
) \\
2\end{array}$ & $\begin{array}{l}\mathrm{Fi}(\mathrm{X} \\
\mathrm{i}- \\
\bar{x})^{2}\end{array}$ \\
\hline $36-38$ & 1 & $\begin{array}{l}3 \\
7\end{array}$ & 37 & $\begin{array}{l}- \\
1 \\
2\end{array}$ & 144 & 144 \\
\hline $39-41$ & 5 & $\begin{array}{l}4 \\
0\end{array}$ & 200 & - & 81 & 405 \\
\hline $42-44$ & 25 & $\begin{array}{l}4 \\
3\end{array}$ & $\begin{array}{r}107 \\
5\end{array}$ & $\begin{array}{l}- \\
6\end{array}$ & 36 & 900 \\
\hline $45-47$ & 26 & $\begin{array}{l}4 \\
6\end{array}$ & $\begin{array}{r}119 \\
6\end{array}$ & - & 9 & 234 \\
\hline $48-50$ & 15 & $\begin{array}{l}4 \\
9\end{array}$ & 735 & 0 & 0 & 0 \\
\hline $51-53$ & 6 & $\begin{array}{l}5 \\
2\end{array}$ & 312 & 3 & 9 & 54 \\
\hline $54-56$ & 3 & $\begin{array}{l}5 \\
5\end{array}$ & 165 & 6 & 36 & 108 \\
\hline $57-59$ & 6 & $\begin{array}{l}5 \\
8\end{array}$ & 348 & 9 & 81 & 486 \\
\hline $60-62$ & 13 & $\begin{array}{l}6 \\
1\end{array}$ & 793 & $\begin{array}{l}1 \\
2\end{array}$ & 144 & $\begin{array}{r}187 \\
2\end{array}$ \\
\hline Total & $\begin{array}{l}10 \\
0\end{array}$ & & $\begin{array}{l}486 \\
1\end{array}$ & & & $\begin{array}{l}420 \\
3\end{array}$ \\
\hline
\end{tabular}

$$
\begin{aligned}
& S D=\sqrt{\left(\frac{\sum f i(x i-x)^{2}}{n-1}\right)} \\
& S D=\sqrt{\left(\frac{4203}{100-1}\right)}=\sqrt{\frac{4203}{99}}=6,4
\end{aligned}
$$

Berdasarkan rumus untuk menghitung standar deviasi data tergolong, maka standar deviasi/simpangan baku adalah 6,4. Hasil tersebut menunjukkan besar kesalahan baku pada skor pada tingkat kepuasan mahasiswa terhadap pelayanan akademik pada Fakultas Program Diploma Pelayaran Surabaya.

8) Kategori skor responden.

Untuk mempermudah mengetahui tingkat kepuasan mahasiswa terhadap pelayanan akademik, maka dibuat rincian menurut kategori nilai. Rincian tersebut meliputi tiga kategori, yaitu; kategori tinggi, kategori sedang, dan kategori rendah, yang ditentukan berdasarkan teori kategorisasi oleh Saifuddin Azwar. Untuk lebih jelasnya dapat dilihat pada uraian berikut:

$$
\text { a. } \begin{aligned}
X<(\mu-1,0 \sigma) \text { Rendah } \\
X<(49-1,0 * 6,4) \\
X<42,6
\end{aligned}
$$


b. $(\mu-1,0 \sigma) \leq X<(\mu+1,0 \sigma)$ Sedang

$(49-1,0 * 6,4) \leq X<(49+1,0 * 6,4)$

$42,6 \leq X<55,4$

c. $X \geq(\mu+1,0 \sigma)$ Tinggi

$X \geq 55,4$

Tabel 4.6 Kategori Skor Tingkat Kepuasan Mahasiswa terhadap Pelayanan Akademik

\begin{tabular}{|l|l|l|l|l|}
\hline \multicolumn{2}{|l|}{ Interval } & $\begin{array}{l}\text { Frekuen } \\
\text { si }\end{array}$ & $\begin{array}{l}\text { Katego } \\
\text { ri }\end{array}$ & $\begin{array}{l}\text { Presenta } \\
\text { se }\end{array}$ \\
\hline $\begin{array}{l}X \\
<42,6\end{array}$ & $\begin{array}{l}36 \\
- \\
42\end{array}$ & 8 & $\begin{array}{l}\text { Renda } \\
\mathrm{h}\end{array}$ & 8 \\
\hline 42, & 43 & 72 & Sedang & 72 \\
$6 \leq X$ & - \\
$<55,4$ & 55 & & & \\
\hline $\begin{array}{l}X \\
\geq 55,4\end{array}$ & $\begin{array}{l}56 \\
- \\
60\end{array}$ & 20 & Tinggi & 20 \\
\hline
\end{tabular}

Berdasarkan tabel diatas memberikan gambaran bahwa kategori hasil angket tentang tingkat kepuasan mahasiswa terhadap pelayanan akademik adalah mahasiswa yang berada dalam kategori tinggi adalah 20 orang dengan persentasi $20 \%$, dan yang berada dalam kategori sedang adalah 72 orang dengan persentasi $72 \%$, sedangkan yang memilih terendah adalah 8 orang dengan persentase $8 \%$. Dengan demikian tingkat kepuasan mahasiswa terhadap pelayanan akademik pada Fakultas Program Diploma Pelayaran Universitas hang Tuah Surabaya berada pada kategori sedang yaitu 72 mahasiswa dengan persentasi $72 \%$

\section{HASIL DAN PEMBAHASAN}

Tingkat kepuasan mahasiswa terhadap pelayanan akademik yang dirasakan mahasiswa selama kuliah di Fakultas Program Diploma Pelayaran setelah memakai atau menggunakan layanan-layanan yang ada, mahasiswa merasa cukup puas terhadap layanan-layanan tersebut, dengan kategori tinggi sebesar 20\%, kategori sedang $72 \%$ dan kategori rendah $8 \%$. Pernyataan di atas berdasarkan perhitungan hasil penelitian di lapangan, hasil yang menjelaskan dari dimensi-dimensi pengukur standar layanan atau jasa dalam kepuasan mahasiswa sebagaimana pendapatnya Philip Kotler pada bab sebelumnya, bahwa layanan yang disajikan menurut penilaian hasilnya telah memenuhi standar. Sehingga mahasiswa merasa cukup puas terhadap layanan akademik yang ada.
Harapan mahasiswa terhadap pelayanan akademik adalah mendapatkan pelayanan yang lebih cepat, tepat, teliti, ramah, selalu siap menolong, selalu berada di tempat dan siap melayani mahasiswa, staf akadenik yang profesional dan ahli pada bidangnya masingmasing, kerapihan dan kebersihan ruangan, serta kelengkapan sarana dan pra-sarana agar menjadi instansi yang lebih baik lagi.

\section{KESIMPULAN DAN SARAN \\ 4.1 Kesimpulan}

Berdasarkan hasil analisis data dan pembahasan yang telah dijelaskan sebelumnya, maka peneliti dapat menarik kesimpulan sebagai berikut:

1. Bentuk pelayanan akademik yang telah dimiliki oleh Fakultas Program Diploma Pelayaran Surabaya seperti bimbingan akademik, pengurusan KRS, ujian tengah semester dan akhir semester, pelaksanaan praktikum, perbaikan nilai, cuti akademik, pengajuan judul skripsi, pengesahan dan penetapan dosen pembimbing, sidang tugas akhir, ujian komprehensif, PPL/kerja praktik,, pengurusan ijazah, pengurusan transkrip nilai, legalisasi ijazah, pelaksanaan wisuda.

2. Kepuasan mahasiswa terhadap pelayanan akademik pada Fakultas Program Diploma Pelayaran Surabaya berdasarkan pengolahan data yang telah dilakukan dari hasil angket tentang tingkat kepuasan mahasiswa terhadap pelayanan akademik adalah mahasiswa yang berada dalam kategori tinggi adalah 20 orang dengan persentase $20 \%$, dan yang berada dalam kategori sedang adalah 72 orang dengan persentase $72 \%$, sedangkan kategori rendah adalah 8 orang dengan persentase $8 \%$. Dengan demikian tingkat kepuasan mahasiswa terhadap pelayanan akademik pada Fakultas Program Diploma Pelayaran Surabaya berada pada kategori sedang dengan persentasi $72 \%$.

\subsection{Saran}

Sehubungan dengan hasil penelitian yang telah dikemukakan di atas dan dengan keterbatasan yang dimiliki oleh penulis dalam penelitian ini, serta implikasinya dalam upaya meningkatkan kualitas pelayanan akademik yang diberikan Fakultas Program Diploma Pelayaran Surabaya kepada mahasiswa sehingga mahasiswa bisa merasa puas. 
Maka saran-saran yang dapat dikemukakan dari hasil penelitian ini adalah sebagai berikut:

1. Kepada Direktur Program Diploma Pelayaran Surabaya agar lebih memperhatikan dan meningkatkan kualitas pelayanan akademik yang diberikan kepada mahasiswa, hal ini berimplikasi pada kepuasan mahasiswa. Jika mahasiswa merasa puas terhadap pelayanan akademik yang diberikan maka akan tercipta loyalitasnya sebagai mahasiswa sehingga, mahasiswa akan semakin rajin dan nama Program Diploma Pelayaran Surabaya akan semakin eksis disebabkan mahasiswa akan menceritakan kepada masyarakat bahwa Fakultas Program Diploma Pelayaran Surabaya adalah salah satu Fakultas terbaik dan terfavorit yang berada di Universitas Hang Tuah Surabaya

2. Kepada Staf Akademik Fakultas Program Diploma Pelayaran Surabaya agar lebih meningkatkan kinerja sesuai dengan tugasnya dalam memberikan pelayanan.

3. Bagi peneliti selanjutnya, peneliti menyarankan untuk melanjutkan penelitian yang serupa dengan melihat faktor-faktor atau aspek-aspek yang lain yang mempengaruhi kepuasan mahasiswa terhadap pelayanan akademik pada Fakultas Program Diploma Pelayaran Surabaya

\section{DAFTAR PUSTAKA}

[1] Azwar, Saifuddin. 2015. Penyusunan Skala Psikologi, Yogyakarta; Pustaka Pelajar.

[2] Suhartini, Eka, 2012. Kualitas Pelayanan Kaitannya dengan Kepuasan Konsumen. Makassar: Alauddin Press.

[3] Tjiptono, Fandy. 2010. Strategi Pemasaran, Edisi 2. Andi Offset, Yogyakarta. 